\title{
LA POTESTAD REGLAMENTARIA DEL GOBIERNO Y LA CONSTITUCION
}

\author{
Por JOSE LUIS CARRO FERNANDEZ-VALMAYOR \\ y RAFAEL GOMEZ-FERRER MORANT
}

\begin{abstract}
Sumario: 1, UNa Cuestión paevia Necesatia: phincipio de legalidad y potestad Reglamentamia. La titularidan de la potestad reglamentaria en el texto constitucional.-II. Sobre la

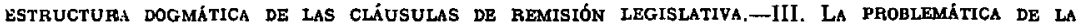

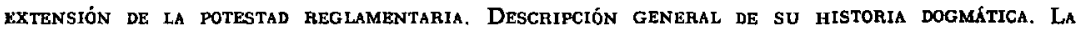
SITUACión actual.-IV. ANálisis del Ámbito de la potestad reglamentaria del Gobierno en IA Constitución: 1. El principio' de reserva de ley. 2. Inexistencia de una reserva reglamentaria. 3. El carácter residual de la potestad reglamentaria del Gobierno. 4. La determinación del posible ámbito residual. 5. La remisión como técnica de habilitar al Gobierno para el ejercicio de la potestad reglamentaria: a) Materias reservadas a la ley orgánica. b) Materias reservadas a la ley ordinaria. c) Posibilidad de admitir la remisión implícita en las materias reservadas a la ley ordinaria. d) Materias objeto de reserva formal. 6. Referencia a la deslegalización. 7. Los denominados reglamentos $u$ ordenanzas de necesidad. 8. Conclusiones.-V. Apunte sobre otras cuestiones relacioNADAS CON IA POTESTAD REGLAMENTARIA: 1. La potestad reglamentaria de los ministros. 2. El procedimiento: en especial, la posible introducción de normas de valor reglamentario a través de convenios y tratados internacionales. 3. Alusión al régimen juridico $y$ control de la potestad reglamentaria.
\end{abstract}

I. Una cuestión previa necesaria: principio de legalidad y potestad reglamentaria. La titularidad de la potestad reglamentaria en el texto constitucional

En la nueva Constitución española no se encuentra una regulación material minuciosa de la potestad reglamentaria y su articulo 97 se limita a declarar que el Gobierno ha de ejercerla

Observación: El presente trabajo constituye el texts de la ponencia presentada por los autores al Seminario sobre *Organización y funcionamiento del Gobierno*, dirigido por el profesor SeBastís MaRtín-Retortillo en el Centro de Estudios Constitucionales. Sin perjuicio de la elaboración conjunta del esquema del mismo, la redacción de los epigrafes I a III corresponde a J. L. Carro y la de los epígrafes IV y V a R. GómEzFeraer.

* Una primera versión de este trabajo fue publicada en el número 87 de la Revista de Administración Pública, correspondiente a septiembre-diciembre de 1978, con cuya autorizacion se reproduce. 
«de acuerdo con la Constitución y las leyes». Una declaración tan general obligará sin duda a los tribunales y a la doctrina que en el futuro se ocupe de este tema capital a realizar una profunda labor de interpretación para determinar el sentido y el alcance de la potestad normativa de la Administración. $Y$ es indudable que en esta labor un problema previo a dilucidar ha de ser necesariamente el de delimitar los contornos precisos del principio de legalidad que solemnemente viene garantizado por el artículo 9-3..$^{\circ}$ en el mismo pórtico del texto constitucional. Principio de legalidad - nos apresuramos a subrayar-entendido a los efectos de nuestro tema en el sentido estricto de confrontación de la potestad de normación administrativa con la ley y no en el más amplio de sometimiento de la Administración al "bloque de la legalidad" (o al "principio de juridicidad», si se prefiere utilizar la expresión de MerkL). Pues bien, desde esta concreta perspectiva ha de afirmarse que el reconocimiento general del principio de legalidad por el citado artículo 9-3. ${ }^{\circ}$ ha encontrado un desarrollo específico en el artículo 103-1. $q u$ obliga a la Administración pública a actuar "con sometimiento pleno a la Ley” y también al Derecho. Significa ello - y merece la pena sea puesto aquí de manifiesto- que nuestro reciente texto constitucional acoge al máximo nivel normativo algo que ya estaba reconocido por nuestra legislación ordinaria (artículos 40-2, 48 y 115 de la LPA, artículo 83 de la LJ) y que se ha dado en llamar principio de la vinculación positiva (positive Bindung) con el que se quiere expresar la necesidad de que cualquier potestad administrativa $-\mathrm{y}$ por consiguiente también la potestad reglamentaria- encuentre precisamente su origen en la norma constitucional o legal que la crea. En este sentido, la norma del artículo $103-10^{\circ}$ viene a significar que el reconocimiento de la potestad reglamentaria ha de reconducirse a la consiguiente previsión constitucional o legal. Están ya muy lejos los tiempos en que alguna doctrina (fundamentalmente italiana) - siguiendo una conocida fórmula de GNeIsT - creyó ver en la discrecionalidad, entendida de manera absoluta, la base $\dot{y}$ fundamento de una potestad reglamentaria independiente paralela a la que tenia por finalidad la ejecución de las leyes; concepción que se puede conectar - aunque por supuesto no iden- 
tificar- con la doctrina germánica de la Ley material (definida desde la perspectiva de la intervención en la propiedad y la libertad) que dejó en manos del Ejecutivo monárquico un importante poder normativo residual que se desarrollaba libremente en el ámbito no cubierto por la reserva legal al que por lo demás -y esto es precisamente lo que distingue la doctrina alemana de los planteamientos italianos- no se le reconocía carácter jurídico.

Mucho debe el «sometimiento pleno» -por utilizar la misma expresión constitucional- de la Administración a la ley a las aportaciones de MerkL, Carré de Malberg y Zanobini desarrolladas en el primer tercio de nuestro siglo como reacción precisamente ante el particular entendimiento de la legalidad al que había llegado la dogmática jurídico-pública tradicional y a la que acabamos de aludir hace un momento. Justamente afirmaba MERkL que toda actividad del Estado para que pueda ser considerada como tal ha de conectarse con una norma jurídica que así lo establezca, norma jurídica que en esta medida se nos ofrece como una regla de atribución (Zurechnungsregel, en la terminología kelseniana). En este sentido, toda acción administrativa ha de estar condicionada por la existencia de una norma previa que admita semejante acción, pues en caso contrario no podría ser considerada como acción de la Administración, imputable a la misma. El principio de legalidad en su acepción más radical significa para el gran autor austríaco que "die gesamte Verwaltung nur auf Grund von Gesetzen ausgeübt werden kann"; construcción perfectamente coherente, por lo demás, con el conocido artículo 18 de la Constitución austríaca de 1920-1929, de innegable influencia kelseniana. Párecida posición matuvo en Francia CarRé de Malberg a partir del artículo 3 de la Ley Constitucional de 1875, que encargaba al Presidente de la República la ejecución de las leyes y al que interpretaba en el sentido de la necesariedad de que toda actividad administrativa cualquiera que fuese su objeto y sus efectos se ejerciese siempre en base a la ley. Según el autor alsaciano, este sistema no habia de denominarse con el concepto de Estado de Derecho, ya que éste no consiste simplemente en hacer depender de habilitaciones legislativas los actos de las autoridades administra- 
tivas que afectasen individualmente a los ciudadanos, sino más exactamente con el nombre de Etat legal, esto es, un Etat dans lequel tout acte de puissance administrative présuppose une loi à laquelle il se ratache et dont il soit destiné à assurer l'exécur tion. Por la misma época también Zanobini había llegado a la misma conclusión a partir de la afirmación de que la Ley constituía para el Estado su propia voluntad interna, inmanente, lo que hacía imposible una desvinculación entre aquélla y la actividad estatal; "la ley -escribía el autor italiano- dice lo que la Administración puede hacer. $O$ sea, mientras el individuo puede hacer todo lo que no le esté expresamente prohibido, la Administración puede hacer solamente lo que la ley expresamente le consiente hacer". Esta concepción de la legalidad tampoco fue extraña al mundo doctrinal alemán de la época (aunque no se puede decir que fuese una actitud mayoritarial y para recordarlo baste citar aquí los nombres de E. KaUfManN, KöTTGEN (ya bajo la Constitución de Weimar) o del suizo FLEINER.

Bien es sabido -y ello ha sido puesto, por lo demás, varias veces de relieve- que fue entre nosotros BaLlbé el que primero operó un cambio radical en la consideración de la relación entre la Administración y la ley criticando la idea dominante hasta entonces de que ésta constituia un simple límite exterior a la actividad libre de aquélla (baste recordar las obras de Santamaría de Paredes o de Fernández de Velasco). En el mismo sentido de los autores antes citados, nuestro autor afirma que la legalidad no limita, sino que condiciona y determina toda la actuación de la Administración; es en él comprobable la influencia de Merkl —al que por lo demás cita en varias ocasionescuando afirma que ya que "solamente un precepto jurídico que hace posible u obligatoria una determinada actuación de la Administración permite poner en relación, referir a la Administración determinados actos de la actividad humana, se desprende que el órgano $y$, en fin de cuentas, la Administración, puede hacer solamente lo que el Derecho le permite, esto es, lo que cae dentro de su competencia". Esta misma línea de argumentación ha sido con posterioridad desarrollada con brillantez por García de Enterría para el que el principio de legalidad opera 
como cobertura legal de toda la actuación administrativa y esta cobertura se realiza a través de un mecanismo técnico preciso que es la atribución de potestades concretas de actuación a la Administración. "Toda acción administrativa -escribe- se nos presenta así como ejercicio de un poder atribuido previamente por la ley y por ella delimitado y construido. Sin una atribución legal previa de potestades, la Administración no puede actuar simplemente."

Los artículos 97 y 103-1. ${ }^{\circ}$ de la Constitución -desarrollo y concreción del principio de legalidad sancionado en el artículo $9-3 .^{\circ}$ - no han hecho otra cosa que constitucionalizar el nuevo sentido de la relación entre la Administración y la ley al que nos estamos refiriendo; la Administración sólo puede ejecutar las potestades que le hayan sido efectivamente concedidas por la Constitución o por la Ley. Ya sabemos que el artículo 97 ha otorgado al Gobierno el ejercicio de la potestad reglamentaria, por lo que se puede decir que sólo él, en el ámbito de la Administración del Estado, goza de una potestad normativa directamente incardinada a la Constitución, necesitando los restantes órganos estatales de habilitaciones legales específicas que les permitan el ejercicio de tal potestad.

\section{Sobre la estructura dogmática de las cláusulas de remisión legislativa}

Interesa, sin embargo, precisar ahora el sentido que puedan tener las fórmulas de remisión de la ley al reglamento (cláusulas de ejecución o de desarrollo, Vollzugsklauseln) después de haber comprobado la existencia en el mismo texto constitucional de una habilitación general para ejercer la potestad reglamentaria en favor de determinados órganos constitucionales (expresamente en favor del Gobiernol que haría posible que estos últimos ejercitasen aquélla de manera "espontánea» para desarrollar cualquier tipo de leyes sin la necesaria existencia previa de expresas fórmulas de remisión. El problema por supuesto no es nuevo, y ya desde principios de nuestro siglo fue conocido y discutido por la doctrina jurídico-pública; así el mismo MERKL 
afirmaba que en principio la función de las fórmulas de remisión era la de designar el órgano administrativo competente para el desarrollo de la ley. El gran autor austriaco reconocía, con todo, que existían fórmulas de remisión en las que no se contenía ninguna especificación sobre la autoridad administrativa encargada de llevar a ejecución la ley por vía reglamentaria, con lo que parece que estaríamos más bien ante una mera repetición de lo establecido de manera general en el texto constitucional; sin embargo, para Merks, esta repetición tendría precisamente como finalidad convertir en un deber la competencia general reglamentaria establecida en la Constitución. En el mismo sentido se habia pronunciado también con anterioridad CAMmeo subrayando tanto en su Corso como en su aportación al Tratado dirigido por Orlando que la fórmula de remisión tiene valor solamente en cuanto impone al Gobierno la obligación de emanar el reglamento y no le otorga una simple facultad. Nuestro A. PoSADA también se había adherido a la misma opinión cuando escribia que «en todo caso, la disposición legislativa relativa a la elaboración de un reglamento tiene la virtud de convertir en obligatoria y precisa una facultad constitucional del Ejecutivo».

Bien es sabido que en Francia el tema del sentido de las fórmulas de remisión se vio envuelto en la polémica sobre la naturaleza de los llamados Réglements d'administration publique expresamente previstos por la norma legislativa y sometidos a un procedimiento especial de emanación. Ha de recordarse aquí cómo gran parte de la doctrina francesa del pasado siglo (en especial, Laferrière, Aucoc, Ducrocq) creyó ver en la cláusula legislativa de desarrollo reglamentario un supuesto de delegación legislativa que transmitiría a este tipo de reglamentos el rango de la ley; la reacción contra tal interpretación partió - como se sabe-de un conocido artículo de Esmein, publicado en 1894, en el que se rechazaba la tesis de la delegación afirmándose que lo único que la ley hacía era inviter le titulaire du pouvoir executif à user de son pouvoir reglémentaire que le había sido reconocido por la Constitución, en concreto por el artículo 3 de la Ley Constitucional de 1875; en definitiva, la ley no haría otra cosa-según el autor francés-que poner en movimiento mediante su «invitaçión" la potestad reglamenta- 
ria que el propio precepto constitucional había concedido al Jefe del Ejecutivo. Más técnicamente Hauriou nos propuso el concepto de «delegación de materias» para una explicación global del fenómeno: el Parlamento delega en el Ejecutivo una parte de la materia que le es propia para que así pueda ejercer sobre ella la potestad reglamentaria que se le ha reconocido constitucionalmente. Desde esta perspectiva la fórmula de remisión operaria, pues, como un mecanismo de apertura de ciertas materias originariamente reservadas a la ley para que el órgano del Ejecutivo designado por la Constitución pudiese ejercitar sobre ellas su potestad reglamentaria originaria y propia. Sin embargo, lo que aquí interesa de modo particular no es tanto el constatar la ausencia en este caso de un supuesto de delega ción legislativa - que los conceptos de "invitación" o de "delegación de materias» se encargaron de subrayar-cuanto el significado jurídico que para el titular de la potestad reglamentaria puede tener la fórmula de remisión contenida en la ley; en este sentido ha de decirse que la doctrina de la época no fue muy radical a la hora de determinar el grado de obligatoriedad de la "invitación» legislativa a la Administración. Asi, mientras HAURIOU no reconocía ningún tipo de obligación en la misma, DUGUIT afirmaba que la única consecuencia que podría vinculäse a la disposición legislativa que encarga al Gobierno la emanación de un reglamento de administración pública es la de retrasar la aplicación de la ley hasta la aparición de este último. En todo caso, tanto para uno como para otro, desde un punto de vista jurídico era imposible imponer al Gobierno el ejercicio de la potestad reglamentaria, pues ésta le venia concedida a aquél por la Constitución y no por el legislador. Para Carré de Malberg la habilitación legislativa-aparte de legitimar el ejercicio de la potestad reglamentaria del Presidente de la República, fuera del campo estricto de la puntual ejecución de las leyes en el que aquél se lleva a cabo de forma “espontánea»-tiene la virtualidad de hacer obligatoria la emanación del reglamento (en virtud de la posición preeminente del Poder Legislativo) y de establecer al mismo tiempo una serie de reglas procedimentales especiales. Con todo se era consciente en este tiempo de que la obligación que podia contener la cláusula de remisión era de 
carácter exclusivamente político y su sanción sólo era posible mediante la puesta en juego de la responsabilidad gubernamental. Ya en nuestros días algún autor (AuBY) ha intentado fundamentar el carácter jurídico de dicha obligación a partir de la función constitucional del Gobierno de garantizar la ejecución de las leyes; la competencia otorgada al Gobierno de ejecutar las leyes no conllevaría - según esta opinión-solamente el derecho, sino también la obligación irrenunciable de ejercerla. DouENCE, completando este tipo de argumentación, ha afirmado que la obligatoriedad del mandato legislativo dirigido al Gobierno se deriva del principio de legalidad que exige la aplicación de las normas legalmente emanadas; la obligación de dictar un reglamento se derivaria, en suma, de la función ejecutiva conferida a las autoridades administrativas por la Constitución y la ley. Sin embargo, el autor francés se apresura a señalar que la obligación sólo existe si el reglamento que ha de dictarse es absolutamente indispensable para la aplicación del texto legislativo, pues en caso contrario nos hallariamos ante una cuestión de oportunidad insusceptible de control por parte del juez administrativo que, por lo demás, es el que determina en cada caso la existencia de una necesidad absoluta de reglamentación de la ley. Por lo que se refiere al establecimiento de un plazo para la emanación del reglamento en la fórmula de remisión, ha de decirse que la doctrina francesa actual (Laubadère, Douence, Devolvé, Montané de La Roque) no le concede ninguna eficacia especial, afirmándose que dicho plazo tiene únicamente un carácter indicativo, si bien el retraso exagerado de la Administración puede constituir una falta que puede dar lugar a responsabilidad (solución sugerida ya por la jurisprudencia del Consejo de Estado: Syndicat des grand's vins de la Côte d'Or, de 24 de julio de 1936 y más recientemente por veuve Renard de 27 de noviembre de 1964 y otros arrêts posteriores).

El ejemplo italiano puede, quizá, ser más ilustrativo de la problemática de las fórmulas de remisión en la medida en que el artículo 1 de la famosa Ley de 31 de enero de 1926, número 100 - considerado hoy vigento bajo la Constitución de 1947intentó disciplinar de manera global la potestad reglamentaria gubernamental admitiendo su ejercicio, entre otros supuestos, 
para la "ejecución de las leyes". Se legitimaba de esta forma -esto es, mediante la previsión general contenida en una ley única-la actividad administrativa de reglamentación de las leyes sin la necesidad de que ésta fuese expresamente reconocida en cada supuesto concreto y sin hacer además distinciones respecto a la materia (administrativa o no) que aquéllas pudiesen regular. Algunos autores de la época (Ranelletri, Saltelli, Preti) consideraron que precisamente con la emanación de la Ley número 100 las cláusulas de desarrollo reglamentario contenidas en las leyes serían absolutamente superfluas; otros (RAGNISco, BetTI), sin embargo, no lo creyeron así y afirmaron que la fórmula de remisión conservaba todavía la función de determinar el alcance de la potestad reglamentaria ya que sin una previsión expresa de la ley concreta aquélla no se podía extender a materias reservadas a la Ley o reguladas anteriormente por ella, es decir, no podían verse legitimados los llamados (un tanto equívocamente) por la doctrina italiana reglamentos delegados. Por otro lado, esta misma dirección doctrinal -interpretando restrictivamente la expresión esiecuzione delle leggi del artículo 1-1..$^{\circ}$ de la Ley de 1926-declaraba también que las concretas fórmulas de remisión podian asimismo tener la función de permitir el desarrollo de leyes que regulasen materias no administrativas, de legitimar el ejercicio de la potestad reglamentaria por órganos distintos del Gobierno (como en el caso de los reglamentos ministeriales, que no fueron regulados por la Ley del 26) o, en fin, de establecer la obligatoriedad de la emanación del reglamento. Modernamente Carlassare se ha ocupado del tema sin llegar, por lo demás, a conclusiones definitivas, sobre todo para el caso en el que la cláusula de desarrollo reglamentario contenida en la ley establezca un plazo concreto dentro del cual debe emanarse el reglamento; la autora italiana constata la imposibilidad de reducir a unidad el significado y valor de las cláusulas legislativas que prevén la emanación de reglamentos, a las cuales, merced a la variedad de su formulación, resulta bastante difícil atribuir una función unitaria. En todo caso, la necesidad de la existencia de dicha cláusula es para Carlassare evidente cuando se trate de los llamados reglamentos delegados o de reglamentos ministeriales. 
En esto la autora no se aparta de la última dirección doctrinal analizada anteriormente.

Entre nosotros, García de Enterría - criticando la doctrina francesa de la «invitación» por presuponer una potestad propia y general de reglamentación en la Administración-ha afirmado que la función específica de la remisión legislativa es precisamente la de habilitar a ésta a dictar el oportuno reglamento. No existe, según él, una potestad reglamentaria general en manos de la Administración que de manera espontánea le permitiese regular cualquier tipo de leyes y en este sentido tampoco podría interpretarse el artículo 97 de nuestra Constitución, que únicamente se refiere al tema de la titularidad de aquella potestad. La Administración, por consiguiente; ni podría desarrollar sin previa habilitación legal todas las leyes que versasen sobre materia no administrativa como, por lo demás - y ello lo subraya nuestro autor - ha venido a reconocer la jurisprudencia de la Sala Civil del Tribunal Supremo, al negar la posibilidad de citar en casación la violación de reglamentos cuya emanación no hubiese sido prevista en el texto legal. Ha de recordarse aquí cómo precisamente en este caso de normación no administrativa ZANOBINI nos hablaba de «atribución excepcional de competencia reglamentaria" y BETTI - criticando justamente la tesis de la superfluidad de las cláusulas de remisión legislativa-nos hacía notar que la disciplina de esta materia ha sido reservada por la Constitución a la competencia del Poder Legislativo y que la posibilidad de una reglamentación espontánea de la Administración en este campo podia suponer una derogación del principio de la división de poderes. Por otro lado, tampoco, según Garcia DE Enterría, puede afirmarse la existencia de una potestad reglamentaria directa de la Administración en el campo de las materias administrativas y ello, en primer lugar, por la posibilidad de que la norma reglamentaria incida, mediante el nowum normativo que establece, en materias reguladas anteriormente por ley, lo que hace necesaria la oportuna habilitación legal y éste es precisamente el sentido de la remisión legislativa; y, en segundo lugar, porque puede tratarse de cuestiones que, aun siendo administrativas, pueden afectar a la esfera juridica de los particulares, lo que hace necesaria también en este caso la 
consiguiente habilitación legal a la Administración para que pueda utilizar la potestad reglamentaria que le ha sido reconocida por la Constitución. En definitiva, pues, el autor llega a similares resultados a los alcanzados por la doctrina italiana de los reglamentos delegados —que ha sido recibida y aceptada bajo la Constitución republicana de 1947-como también por la alemana de los reglamentos jurídicos que ha encontrado su plasmación positiva al máximo nivel normativo-y esto tiene a su favor-en el artículo 80 de la Ley Fundamental de Bonn de 1949. (Desgraciadamente no existe en nuestro texto constitucional de 1978 una norma semejante que hubiera determinado de forma definitiva el sentido $\mathrm{y}$ el alcance de las remisiones legislativas.) Es claro que existen todavia algunos puntos de la teoria del reglamento que es necesario clarificar (asi el saber si el concepto de reglamento organizativo incluye la normación dictada en el marco de lo que se viene llamando relación especial de poder o de supremacía especial, o el de si el reglamento que afecte de modo exclusivamente favorable la esfera jurídica de los ciudadanos exige la previsión de una habilitación legislativa específica), pero lo que se pretende aquí subrayar por el momento es sencillamente la convergencia -o el consenso, por utilizar una palabra más familiar al lector español-que se viene decantando en este tema al analizar su historia dogmática. Sin embargo, estas consideraciones nos llevarian directamente al problema de la extensión de la potestad reglamentaria que será analizado más adelante, pero que indudablemente se encuentra íntimamente unido al problema del alcance y significado de las cláusulas de remisión al reglamento contenidas en las leyes y a las que nos estamos refiriendo ahora. Ciñéndonos, pues, a este último, interesa destacar que las cláusulas de remisión al reglamento adquieren, tanto en el campo administrativo cubierto por la primacia o la reserva legal como en el campo no administrativo por las razones expuestas, un contenido positivo que se traduce en una verdadera habilitación en favor de la Administración para que pueda ejercer su potestad reglamentaria en dichos campos. Si la Administración no necesitase de tales habilitaciones y dispusiese siempre y necesariamente de poderes propios para dictar reglamentos la práctica de las cláusulas de remisión 
legislativa - ha afirmado García de Enternía-carecería de sentido. Por el contrario, creemos en principio, y a reserva de ulteriores precisiones, que la Administración ( $y$, en concreto, el Gobierno, en virtud del artículo 97 de la Constitución) podrá de forma espontánea ejercer su potestad reglamentaria para regular la organización, servicios y prestaciones administrativas (respetando, por supuesto, los principios de primacía y reserva legal) y para completar y desarrollar leyes administrativas cuando ello fuese absolutamente indispensable para su ejecución y no incidiese en materias de reserva material de ley; bien es verdad que no se nos escapa que este segundo supuesto puede muy bien confundirse con el primero en la medida en que muy frecuentemente la ejecución de una ley depende de la emanación de simples reglas organizativas por parte de la Administración.

Las cláusulas de remisión legislativa entendidas como habilitación permiten además - y ello ha sido hecho notar por García DE Enterria-explicar la obligación de la Administración de dictar un reglamento; la omisión funcional de actuación que se deriva de una atribución positiva de potestad normativa puede dar lugar a una falta que fundamente una responsabilidad administrativa; responsabilidad que puede extenderse también al supuesto antes contemplado de potestad reglamentaria cespontánea” ejercitada con el fin de desarrollar una ley administrativa. cuando ello resulte absolutamente indispensable para su ejecución.

III. La problemática de la extensión de la potestad reglamentaria. Descripción general de su historia dogmática. La situación actual

Mucho se ha podido deducir ya respecto de la extensión de la potestad reglamentaria del somero estudio realizado sobre la estructura dogmática de las cláusulas de remisión al reglamento contenidas en las leyes. Si se analiza la historia dogmática del poder normativo de la Administración podrá comprobarse cómo todas las dudas y perplejidades respecto a su extensión giraron en torno al problema de determinar con la mayor claridad po- 
sible hasta qué punto aquél podia existir con independencia de las concretas leyes en las que debía apoyarse caso por caso.

Bien es sabido que el proceso de extensión de la potestad reglamentaria tiene históricamente su origen en la Restauración, con independencia de que bajo las Constituciones revolucionarias pudiese ya detectarse, como nos ha señalado Moread, una importante actividad normativa del Ejecutivo, especialmente en el período napoleónico. Pues bien, lo que nos interesa destacar aqui es que la nueva estructuración que se opera entre el Legislativo y el Ejecutivo en el momento de la Restauración - y ello ha sido repetidamente puesto de manifiesto- es la inmediata consecuencia de la necesidad de conciliar las exigencias planteadas por la tradición de la monarquía restaurada, por un parte, y los principios de libertad consagrados por la Revolución, por otra; principios que a pesar del cambio político efectuado venían considerados como una adquisición histórica definitiva y permanente. Sin embargo - y ello no podía ser menos, dadas las circunstancias históricas del momento-; en la nueva estructuración del Estado se va a reconocer al «principio monárquico» una función prevalente sobre la legitimidad democrática representada por Cámaras legislativas; posición de prevalencia que se actúa teóricamente a través del reconocimiento al monarca de una potestad de reglamentación o de ordenanza independiente, sólo limitada parcialmente por las materias que se había reservado el Parlamento, y que encontró su primera plasmación positiva en el artículo 14 de la Carta constitucional francesa de 1814 que permitía al Rey dictar les réglements et ordonnances pour l'execution des lois et la sûreté de l'Etat, lo que suponia el reconocimiento de una potestad reglamentaria general en manos del monarca en materia de ejecución de las leyes y en materia de policia; sin embargo, será la Revolución de julio la que de forma definitiva dirimirá el contencioso planteado sobre el alcance del poder real de reglamentación, sobre todo en el campo de la sûreté de l'Etat, en la que se habían basado las famosas Ordenanzas de Carlos $\mathrm{X}$ que provocarian precisamente el estallido de aquélla. El artículo 13 de la Carta constitucional de $1830-q u e$ tanta influencia tuvo en otros textos constitucionales europeosestablecerá que el Rey fait les, réglements et ordonnances neces- 
siores pour l'execution des lois sans pouvoir jamais suspendre les lois elles mêmes ni dispenser de leur exécution; es precisamente a partir de este momento cuando queda definitivamente consagrada la base constitucional de la potestad reglamentaria alrededor de la fórmula de la «ejecución de las leyes» (que acoge posteriormente el artículo 3 de la Ley Constitucional de 1875), cuyo alcance concreto evolucionará en sentido expansivo en los años posteriores por obra de la interpretación que de ella hará la doctrina francesa de finales del xix y principios del $\mathrm{xx}$. No debe olvidarse, por otra parte, que muchas de las discusiones sobre el alcance efectivo de la potestad reglamentaria en este período histórico venían en gran medida motivadas por la ausencia en el texto constitucional francés de $\mathbf{1 8 7 5}$ de una clara delimitación entre el ámbito reservado a la ley y el específico del reglamento (lo que no ocurría, por ejemplo, en muchas Constituciones alemanas del XIX); de aquí que la polémica francesa sobre los reglamentos girase fundamentalmente alrededor de la distinción entre «reglamentos en virtud de Ley» y «reglamentos espontáneos", incluyendo ambos conceptos, para estar de acuerdo con la norma constitucional, en una ejecución de las leyes entendida en sentido amplio, esto es, como "ejecución de la legalidad" y no de una ley concreta.

No pretendemos tratar aquí la rica polémica que sobre nuestro tema se produjo en Francia en aquellos momentos, pues ello desbordaría el marco que se ha fijado esta ponencia. Sin embargo, si quisiéramos mencionar dos nombres que de alguna forma personificaron dos posiciones contrarias respecto al tema de la extensión de la potestad normativa de la Administración: Carré de Malberg y Hauriou. Para el primero, el concepto de ejecución de las leyes (en sentido amplio) viene a identificarse con el de habilitación legislativa a la Administración (presidente de la República) para ejercer la potestad reglamentaria que le había concedido el artículo 3 de la Ley Constitucional de 1875, y no como desarrollo reglamentario de una ley concreta o como base justificativa de una potestad reglamentaria independiente en determinados campos que también se englobaria en un concepto amplio - según algunos-de ejecución legal. La Constitución -afirma nuestro autor-define el reglamento únicamente 
por su subordinación a la ley, subordinación radical en la medida en que la Administración sólo puede utilizar la potestad reglamentaria si una ley previa se lo permite. Hay que decir, con todo, que la habilitación en CarRÉ viene considerada desde una perspectiva estrictamente formal y en este sentido no se encuentra en forma alguna limitada por el principio de reserva material de ley, y ello porque-como ya sabemos-en la Ley Constitucional francesa de 1875 este principio no estaba consagrado. Para Hauriou, por el contrario, las cosas son de muy diferente manera, pues reivindica para la Administración un ámbito propio donde ésta pudiese ejercer su potestad reglamentaria con independencia de toda habilitación de ley concreta; y este ámbito lo concreta el gran autor francés en la organización administrativa (réglamentation des services publics)' y el campo del orden público (réglamentation de police), sin dejar de reconocer que en este último caso la vinculación a la ley debe ser más estricta que en el primero. Sin entrar ahora a analizar más detenidamente las posiciones de estos dos autores, ha de señalarse, sin embargo, cómo la jurisprudencia del Consejo de Estado francés en sus célebres arrêts Herriès y LABONNE acabó por inclinarse hacia los planteamientos del decano de Toulouse.

También en Alemania el tema de la extensión de la potestad reglamentaria está íntimamente ligado a los avatares del principio monárquico que a nivel supraestatal habia encontrado su consagración en el conocido artículo 57 del Acta Final de Viena de 1820 , aunque, por supuesto, con anterioridad a esta fecha habia tenido ya acogida en los textos constitucionales de algunos territorios alemanes. Interesa recalcar -y así lo ha hecho, entre otros, JESCE-que en las monarquías constitucionales alemanas del xIx el principio monárquico constituye un elemento estructural decisivo que condiciona el campo asignado a la ley y al reglamento en la medida que a favor del monarca - y ello como ya sabemos es típico de los inicios de la Restauración-juega una presunción de competencia normativa residual en virtud de la cual le corresponden todas aquellas materias que no han sido expresamente atribuidas a otros órganos del Estado; aquí está precisamente el sentido originario de la "reserva de ley", que más que operar en el momento en que se configura como una 
garantía de libertad constituía un criterio de reparto de competencia normativa como forma de conciliar la tensión entre dos principios -el monárquico y el democrático-que aparecían como antitéticos en el periodo de la Restauración. Sin embargo, hay que decir que no todas las Constituciones germanas que se empiezan a promulgar en el primer tercio del xIx delimitaron de manera concreta el ámbito de la reserva legal, pues mientras unas-por influencia de VoN STEIN-lo determinaron expresamente a través de la fórmula "propiedad-libertad", otras - y en especial la Carta Constitucional Prusiana de 1850-sometieron sencillamente toda la legislación a la aprobación del Parlamento sin determinar su ámbito material. Ello obligó-como es sabido-a una ingente labor interpretativa, polarizada alrededor del artículo 62 de la citada Carta prusiana de 1850, y centrada en el concepto de ley, en un intento de llegar a la determinación de su ámbito material concreto. No se puede, naturalmente, traer a estas páginas todo el desarrollo de la doctrina de la ley material, bástenos con indicar aqui que una parte importante de la misma (por todos, ANschütz) llegó por vía interpretativa a la conclusión de que el concepto de ley $-\mathrm{y}$, en definitiva, el mismo concepto de Derecho- sólo era explicable a partir de la fórmula "propiedad-libertad". Todo ataque (Eingriff) a la esfera de la propiedad y libertad ciudadanas se hace dependiente de una previa intervención parlamentaria con la consecuencia de que todo reglamento que afectase a dicha esfera -al constituir por ello una verdadera ley material (en definitiva, una norma jurídica, en virtud de la determinación de lo jurídico que a partir de aquel concepto se efectúa) reservada por la Carta constitucional prusiana al Parlamento- habria de venir necesariamente legitimado por una previa habilitación legislativa. De aquí la denominación de Rechtsverordnungen (reglamentos «jurídicos») que este tipo de reglamentos recibe y con la que se quiere hacer notar no sólo la necesidad de habilitación legislativa previa, sino también - como ha quedado ya apuntado-su categoría de normas jurídicas en cuanto que Derecho desde la perspectiva de la doctrina de la ley material era sólo lo que afectaba a la esfera juridica de los ciudadanos, en definitiva, lo que se desenvolvía en el marco de una relación de 
supremacía general o relación general de poder, si se prefiere utilizar estos términos. Desde esta perspectiva, la potestad reglamentaria independiente de la Administración se circunscribia al ámbito interno administrativo -identificado por la doctrina de la ley material con el ámbito del no-Derecho-, en donde aquélla podia dictar libremente Verwaltungsverordnungen (reglamentos "administrativos») no considerados como verdaderas normas jurídicas dada la limitación operada de lo jurídico a las relaciones intersubjetivas. De esta forma el mundo de la organización, de las relaciones de supremacía especial, venía así a constituir el campo propio de la potestad reglamentaria de la Administración; potestad reglamentaria que desde el particular planteamiento germano de aquel tiempo se ejercía en un mundo ajeno al Derecho.

Ha de añadirse, por último, que la necesidad de habilitación para los reglamentos jurídicos fue entendida en Weimar, a partir de la técnica de las Ermächtigungsgesetze, desde un punto de vista estrictamente formal, permitiéndose con ello verdaderas habilitaciones globales o indeterminadas en favor del Ejecutivo (un poco a como en Francia lo permitía la teoria de CARRÉ DE MALberg, que ya hemos visto), desnaturalizándose así el sentido de garantia que éstas podian tener; ésta fue precisamente la razón de la introducción en la actual Ley Fundamental de Bonn de la norma del artículo 80, que exige de la ley de habilitación, aparte de su cita expresa en cada reglamento, el establecimiento del contenido, finalidad y extensión de las facultades otorgadas al Ejecutivo; es interesante destacar cómo uno de los comentaristas de la Ley Fundamental - Maunz-considera al citado artículo 80 una manifestación especial (besondere Ausprägung) del artículo $20-3 .^{\circ}$, que somete al Ejecutivo «a la Ley y al Derecho", y que ha sido de innegable influencia en la redacción del artículo $103-1 .^{\circ}$ de nuestra Constitución.

La doctrina italiana del xIx también intentó, al igual que la francesa, determinar el alcance de la potestad reglamentaria de la Administración a partir de una interpretación amplia del término esecuzione delle leggi que utilizaba el artículo 6 del Estatuto Albertino de 1848 (decisivamente influido en su redacción por la Carta francesa de 1830); así, al lado de los reglamentos 
ejecutivos en sentido estricto, esto es, de aquellos que se limitaban a desarrollar materias que se encontraban ya materialmente reguladas por la ley, se empezó a reconocer la existencia de unos reglamentos independientes, aunque sobre su significado $\mathrm{y}$ extensión no existiese un completo acuerdo en la doctrina del tiempo. En efecto, para Cammeo - uno de los autores que se preocupó más del problema, como lo demuestra su extensa contribución al Tratado colectivo dirigido por Orlando-estos reglamentos independientes venian a identificarse prácticamente con los que en aquel tiempo se denominaban «reglamentos de prerrogativa", esto es, aquellos reglamentos emanados directamente por el Rey en ausencia de toda ley previa en una serie de materias especificadas concretamente en el Estatuto; bien es verdad también que nuestro autor, mediante una interpretación amplia de los articulos del Estatuto referidos a este tipo de argumentos, incluía en el ámbito de la potestad reglamentaria independiente, entre otras cosas, toda la materia de la organización administrativa. En base a una argumentación - no exenta en algunos momentos de cierta vacilación-, Cammeo rechazaba la posibilidad de existencia de reglamentos independientes, fuera del citado caso de los "reglamentos de prerrogativa», en base principalmente al principio general de libertad en favor de los ciudadanos y al principio de la división de poderes. Lo que interesa destacar igualmente es que en Italia nunca se llegó -como en el caso alemána negar categoría jurídica a los reglamentos independientes, sea cual fuese el significado que a éstos se les adjudicase, y en este sentido la critica de CAMMEo fue especialmente contundente. Zanobini, por su parte, en un célebre artículo publicado en 1922 , consideró como reglamentos independientes aquellos reglamentos que, basados en una previa habilitación legislativa, desarrollaban materias no reguladas materialmente por la ley de habilitación cotra vez el entendimiento puramente formal de este concepto, que ya hemos ,visto ser la característica de otros autores); en todo caso, en nuestro autor el concepto de reglamento independiente no. era en absoluto identificable con el de reglamento praeter legem. Sin embargo, esta última categoría era una práctica administrativa cuya realidad en aquel tiempo era innegable y la doctrina intentó encontrarle como fuese una vincula- 
ción con la legalidad mediante la afirmación de la existencia de una habilitación consuetudinaria (a la que apelaba, por ejemplo, CAMmeo para justificar la potestad reglamentaria independiente en materia de organización) o de una habilitación implícita incluida en el conferimiento de una potestad discrecional a la Administración (Romano, Ranellettr).

Al lado de la categoria de los reglamentos independientes se construyó la de los llamados reglamentos delegados; se trataba de reglamentos a los que la ley había autorizado a regular materias a ella reservadas por el texto constitucional o reguladas anteriormente a nivel legislativo. Eran, en definitiva, los reglamentos jurídicos alemanes necesitados de previa habilitación legislativa por afectar la esfera jurídica de los ciudadanos, aunque - como se ha subrayado-en Italia no operaron como criterio delimitador de lo jurídico.

La citada Ley de 31 de enero de 1926, número 100, abordó en su artículo 1 la regulación unitaria de la potestad reglamentaria del Gobierno, distinguiendo entre reglamentos ejecutivos, independientes (basados en la discrecionalidad administrativa o-por decirlo con palabras de la Ley-en el uso delle facoltá spettanti al potere esecutivo) y de organización (en cuya materia, con algunas excepciones, la Ley llevaba a cabo una deslegalización). En definitiva, la Ley número 100 vino a operar como una habilitación legislativa general en favor del Gobierno, no sólo permitiéndole desarrollar las leyes de forma "espontánea» (claro está, siempre que no se vieren afectados los principios de reserva y primacía legal), sino también, y sobre todo, consagrando positivamente el ámbito propio de la potestad reglamentaria gubernamental, ya que los llamados reglamentos delegados - necesitados en cada caso de habilitación legislativa específica-quedaban fuera de su ámbito. La ley de 1926 vino a regular, pues, lo que Betri llamó petere regolamentare di competenza ordinaria, mientras que los reglamentos delegados entraban en el ámbito del denominado por este mismo autor potere regolamentare di speciale attribuzione.

Én líneas generales, la doctrina italiana actual considera que el artículo 1 de la Ley de 1926 ha mantenido su vigencia aun después de la promulgación de la Constitución democrática de 1947. La única dificultad (si exceptuamos las matizaciones de Carlassa. 
RE derivadas de su comprensión de la legalidad) se ha planteado en materia de reglamentos de organización, ya que el artículo 97 de la Constitución italiana ha establecido que $i$ pubblici uffici sono organizzati secondo disposizioni di legge (norma muy semejante, por lo demás, con el artículo 103-2 de nuestro texto constitucional); la disposición constitucional ha sido normalmente interpretada en sentido restrictivo (excluyendo, por ejemplo, el funcionamiento de los órganos estatales al que se refería la Ley de 1926), si bien se ha afirmado también (Guarino) que la potestad reglamentaria en materia de organización, a partir de la Constitución, debe encontrar en cada caso fundamento en una expresa disposición de ley. ZaNoBinI, por su parte, consideró derogada la Ley de 1926 en materia de reglamentos de organización después de la entrada en vigor de la Constitución, y Nigro, al analizar monográficamente el tema de la función organizativa, afirmó que en todo caso al sentido de la norma del artículo 97 era la de establecer un reparto en materia de organización entre el Legislativo y el Ejecutivo, limitando la competencia del primero únicamente al establecimiento de las directrices fundamentales en base a las cuales habría de desarrollarse la actividad reglamentaria del segundo en este campo. (No ha de olvidarse que este autor llega incluso a construir, a partir de estos presupuestos, una «riserva dell'amministrazione» en materia organizativa.J

Por lo que a nuestro país se refiere, la historia dogmática de la potestad reglamentaria tiene su punto de partida en la fórmula consagrada por el artículo $171-10^{\circ}$ de la Constitución gaditana (heredada del art. V del Nuevo Reglamento de la Regencia), según la cual competía al Rey expedir los decretos, reglamentos $e$ instrucciones que crea conducentes para la ejecución de las leyes; comenzaba así una determinación de la potestad reglamentaria que se mantendrá prácticamente invariable a lo largo de todo el desarrollo constitucional español hasta el texto republicano de 1931 y que se vinculará a la interpretación de la fórmula "ejecución de las leyes". En todo caso lo que si puede afirmarse es que la doctrina española del xix no efectuará una profunda teorización sobre la posibilidad de una potestad reglamentaria independiente de las leyes, siendo ésta siempre considerada como 
puntual ejecución de las mismas. Bajo la Constitución de 1845 afirmaba ColmeIro que el reglamento puede producirse aespontáneamente", sin necesidad de expresa previsión legislativa, con la finalidad de ejecutar las leyes y siempre que no incidiese en materias a ella reservadas; distinguía en este sentido los reglamontos ejecutivos dictados de forma espontánea de los reglamentos «delegados» necesitados en cada caso de expresa habilitación legislativa (delegación es el término utilizado por nuestro autor), pero en su obra no se encuentra - a pesar de la ambigüedad de alguna de sus expresiones-una afirmación clara de la posibilidad y alcance de una potestad reglamentaria independiente de leyes previas.

Fue, sin embargo, en la doctrina española del primer tercio del siglo $\mathrm{xx}$ donde la fórmula constitucional de la ejecución de las leyes encontró su más amplia interpretación. Así, para A. PoSADA la fórmula significaba que el reglamento no podia modificar la ley ni violar los derechos fundamentales; lo que, en otros términos, significaba que la potestad reglamentaria de la Administración se veía únicamente limitada por los principios de primacía y reserva legal y no reducida a una labor estrictamente ejecutiva de las leyes (labor que, por lo demás, la Administración también podía realizar de manera espontánea). Gascón y Marín escribia que «hay que admitir que en el silencio de la ley hay que presumir la potestad reglamentaria de la Administración, limitada por las garantías que son para los ciudadanos los preceptos de la Constitución y de las leyes que confieren derechos a los súbditos y por los mismos principios generales del Derecho, que no deben poder ser contradichos por el poder discrecional de los órganos del Poder Ejecutivo». A. Royo-Villanova llegó a afirmar que el fundamento de los reglamentos independientes, de innegable existencia en la práctica, no habria que ir a buscarlo en la fórmula de la ejecución de las leyes interpretada en su más amplio sentido, sino en la costumbre constitucional por la que en ausencia de ley aplicable se reconocía a la Administración la facultad de dictar normas jurídicas sobre materias, por supuesto - añadiremos por nuestra cuenta- no sometidas a la reserva de ley ni congelado su rango a nivel legislativo (con- 
viene, quizá, recordar aquí que ésta era la posición de CAMMEo respecto de los reglamentos de organización).

Puede decirse que en todos estos autores está latente - aunque no claramente manifestada-la idea de que el campo de la potestad reglamentaria independiente viene a determinarse a partir del concepto de discrecionalidad y en ellos el reglamento independiente tiende a desarrollar su virtualidad en el campo de la organización administrativa. Es, por lo demás, significativo que por iniciativa de Royo se acepte la clasificación de STEIN y que algún autor (García Oviedo) al describirla fundamente los reglamentos independientes en la discrecionalidad administrativa. FERNÁNDEZ dE VELASCo más claramente afirmaba la posibilidad de reglamentos en ausencia de ley "según los principios doctrinales que regulan el ejercicio de la facultad discrecional" y determinaba de una manera significativa la materia reglamentaria en "el condicionamiento jurídico de los servicios públicos, completando o supliendo las leyes".

La moderna doctrina española - con independencia de la tesis de la reserva reglamentaria definida bajo la legalidad de las Leyes Fundamentales e insostenible hoy en el marco de la Constitución democrática-no se diferencia de manera fundamental de los autores hasta ahora citados en lo que se refiere al ámbito de la potestad reglamentaria independiente; así, Garrido Falla la hace coincidir con los reglamentos de organización y con los dictados para regular el ejercicio de poderes discrecionales administrativos. García de Enterría - cuya posición ha quedado ya reflejada por lo dicho en páginas anteriores-concreta de modo más estricto en el ámbito organizativo interno el campo propio de la potestad reglamentaria independiente; ámbito que por derivación extiende a las llamadas relaciones de supremacía especial. Garcia-Trevijano, por su parte, incluye igualmente en la potestad reglamentaria independiente los reglamentos orgánicos y de servicios y además los referentes a la actividad de prestación siempre que no incidan en materias reservadas.

En líneas generales $-\mathrm{y}$ con independencia de una serie de matizaciones no esencialmente relevantes $y$ que no se pueden hacer en el marco modesto de una ponencia-puede afirmarse 
que una cierta convergencia es perceptible en la historia dogmática de la potestad reglamentaria tanto en nuestro pais como en otros de estructura jurídica semejante. El campo propio y específico del reglamento independiente tiende a acantonarse en el ámbito interno administrativo corganización, relación de supremacía especiall mientras que en el campo de las materias no administrativas $\mathrm{y}$, en general, en el de las relaciones con los ciudadanos se afirma constantemente la necesidad de la oportuna habilitación legal. Desde esta perspectiva podría ya afirmarse que la potestad reglamentaria que el articulo 97 de nuestra Constitución atribuye al Gobierno sólo es utilizable por éste, en ausencia de ley previa, en el ámbito interno o doméstico de la Administración, argumentación que viene avalada por ese "sometimiento pleno a la ley y al Derecho" que exige de la Administración el artículo $103-10^{\circ}$ del texto constitucional y que trasluce un entendimiento de la legalidad que hace exigible - como bien lo ha puesto de manfiesto la moderna dogmática alemana a propósito de una norma semejante contenida en su Constitución - una específica habilitación legislativa para todo reglamento que afecte gravosamente la esfera jurídica de los ciudadanos; habilitación que por las mismas exigencias de las materias reservadas a la ley $\mathrm{y}$ en el último término también por el mismo artículo 103-1. ${ }^{\circ}$ había que entender en sentido material, no aceptándose habilitaciones indeterminadas o globales frente a los derechos de los ciudadanos. Hubiese sido deseable que nuestro texto constitucional hubiese expresamente sancionado esta exigencia, pero en todo caso ella está claramente implícita en el mismo, en los términos que luego precisaremos.

Si hemos dicho que el campo propio de la normación administrativa es el ámbito interno de la Administración, hay que matizar enseguida que el texto constitucional de 1978 ha incidido también en él de manera importante limitando el alcance de esta potestad reglamentaria doméstica al establecer el artículo 103-2. que, "los órganos de la Administración del Estado son creados, regidos y coordinados de acuerdo con la ley», disposición que ha de ponerse en relación con los artículos $98-1 .^{\circ}$ y 8-2..$^{\circ}$, este último referido en la organización militar. El mundo de la organización administrativa se ve vinculado de esta forma a la . 
ley dejando de estar absolutamente a la merced de la normación reglamentaria independiente, como tradicionalmente así ha sido. Con todo, la expresión "de acuerdo con la ley» de la norma constitucional citada permite afirmar que en materia organizativa - como tendremos ocasión de comprobar más adelante-no estamos ante una vinculación capilar a la ley, sino que más bien ésta ha de limitarse o puede limitarse a establecer las grandes líneas del esquema organizativo estatal dejando a la potestad reglamentaria todo el resto, esto es, su desarrollo concreto y específico. Esta es, por lo demás - como ya sabemos-, la interpretación que la doctrina italiana ha dado a una norma semejante de su Constitución que hemos transcrito anteriormente.

También, por lo que se refiere al ám̄bito interno de la Administración, ha de ponerse de manifiesto que las llamadas relaciones de supremacia especial han sufrido en nuestros días una transformación radical que impide sin más dejarlas a la libre disponibilidad reglamentaria de la Administración, como exigía la doctrina tradicional de cuño germánico; es además sintomático que esta misma doctrina venga intentando, mediante apelación a conceptos tales como habilitación constitucional global, habilitación consuetudinaria o sumisión voluntaria del ciudadano a las condiciones de la relación de sujeción especial, una vinculación más clara de ésta con la legalidad. No podemos, por supuesto, entrar ahora a analizar la problemática del alcance de la reserva de ley en este campo-que merecería por sí misma un estudio más detenido-, pero de todos modos es necesario afirmar aquí que gran parte del ámbito tradicional adjudicado a las llamas relaciones de supremacía especial se encuentran hoy en día-por mor de nuestro reciente texto constitucional-sometido al imperio de la ley parlamentaria, de manera que gran parte de los supuestos de especial sometimiento de los ciudadanos a la Administración -al menos en lo que ULE ha llamado gráficamente Grundverhältnis- no encuentran ya su legitimación en la potestad doméstica de la Administración, sino en el mismo texto legal. $Y$ con esto no se quiere decir que se haya llegado a una reserva legal total en este ámbito interno administrativo (como, por lo demás, ha defendido una importante doctrina moderna), pues todavía serían del patrimonio normativo administrativo lo 
que el citado autor alemán ha denominado "relaciones de funcionamiento" (Betriebsverhältnis) dentro de una relación de supremacia especial, incluyendo el supuesto de los concesionarios de los servicios públicos.

En el campo o ámbito externo de la Administración el problema actualmente planteado es el de saber si la reserva legal -o lo que es lo mismo, la necesidad de habilitación legislativa previa-debe extenderse a todo tipo de normación que afecte del modo que sea a la esfera jurídica privada o debe limitarse, por el contrario, únicamente a aquella que incida de manera gravosa en los derechos ciudadanos, lo que constituyó tradicionalmente su campo de protección. En favor de una reserva total que incluyese también el campo prestacional se han barajado distintos argumentos en cuya descripción pormenorizada no podemos entrar ahora (cambio material del contenido del concepto de libertad, exigencia del principio democrático constitucionalmente garantizado, intima interdependencia entre limitación y prestaciones), pero contra los que también se ha alzado una importante doctrina reivindicando precisamente dicho campo como el propio y específico de la actividad normativa de la Administración (entre nosotros hemos visto cómo García-TreviJano no exigía previa habilitación legislativa para los reglamentos referentes a la actividad de prestación). En todo caso debe precisarse que la temática del alcance del principio de legalidad en el marco de la llamada Administración de prestación se ha planteado fundamentalmente en materia de subvenciones antes que en el ámbito de las «relaciones de funcionamiento" de los servicios públicos que se considera de pertenencia interna de la Administración. De todas maneras la solución que se adopte al respecto es tributaria de la concepción de la legalidad de la que se parta, como ya hemos tenido ocasión de poner de manifiesto al comienzo de la ponencia. Sea como fuere-sea que se deje este campo a la normación administrativa o que se afirme la necesidad, también aquí, de una previa habilitación legislativa (incluyendo la contenida en la Ley del Presupuestol-, lo que nunca puede constituir es un campo "libre de Derecho", pues en todo caso, y con independencia de las vinculaciones constitucionales específicas, los principios generales del Derecho y el principio de igualdad 
deben jugar aquí un papel preponderante. En todo caso más adelante tendremos ocasión de considerar esta problemática a la luz de nuestro texto constitucional.

En definitiva, pues, creemos que puede afirmarse que, aparte de los concretos problemas planteados respecto a la actividad de prestación y con las matizaciones realizadas en materia organizativa, existe un acuerdo tácito general respecto del alcance de la potestad reglamentaria que conviene tener presente a los efectos de un análisis más detenido de nuestro texto constitucional, que se realiza a continuación. Este acuerdo tácito puede concretarse en dos premisas fundamentales: a) El ámbito interno administrativo es el propio de la potestad reglamentaria independiente, con las salvedades de la normación constitucional sobre las grandes líneas de la organización administrativa y de la llamada «relación esencial» dentro de las relaciones de supremacía especial (esto es, la referida a su constitución, modificación o extinción de la relación). b) El ámbito externo o relacional se encuentra dominado por el principio de la previa habilitación legislativa que legitima la potestad reglamentaria de la Administración siempre que ésta afecte a las materias de reserva legal. En lo que se refiere al mundo prestacional, el problema es discutible en base sobre todo a argumentos de tipo metajurídico, como se verá más adelante, y siempre que no afecte a las materias de reserva legal.

\section{Análisis del ámbito de la potestad reglamentaria del Gobierno en la Constitución}

Las consideraciones anteriores permiten ya pasar al estudio concreto del ámbito de la potestad reglamentaria del Gobierno en la Constitución.

Debe hacerse notar que la atribución del ejercicio de la potestad reglamentaria al Gobierno no ofrece duda alguna, pues la Constitución, como ya se ha señalado, viene a efectuarla de forma expresa en su artículo 97-1..$^{\circ}$ En cambio, lo que ya no precisa la Constitución es el ámbito de la potestad reglamentaria, una vez que la inspiración francesa de la redacción inicial (reserva de ley $\mathrm{y}$-por exclusión-reglamentaria) ha sido sustancialmente 
modificada. De aquí que el intérprete que pretenda ofrecer una respuesta a este tema se vea obligado a efectuar un análisis de la Constitución con objeto de inducir cuál sea la solución aplicable.

A tal efecto parece necesario determinar, en primer lugar, cuál es el ámbito - si existe-de la potestad reglamentaria del Gobierno para dictar reglamentos independiente de la ley, es decir, al margen de una habilitación legal; en segundo término, se considerará en qué medida este ámbito de la potestad reglamentaria propia puede complementarse a través de las técnicas de la remisión y la deslegalización; por último, haremos también una referencia a los denominados reglamentos $u$ ordenanzas de necesidad.

En esta línea, y ya con referencia específica a la primera cuestión planteada, conviene poner de manifesto algunos de los principios de la Constitución, como son el de reserva de ley y el de inexistencia de una reserva reglamentaria (primacía de la ley), que nos llevarán a la conclusión del carácter residual de la potestad reglamentaria del Gobierno, independiente de la ley.

\section{EL PRINCIPIO de RESERVA DE LEY}

La constitución contiene una regulación bastante detenida deI principio de reserva de ley, es decir, de aquellas materias que necesariamente han de ser reguladas por normas de este rango (reserva material). Y más aún, dentro de este principio, la Constitución distingue entre materias reservadas a la ley orgánica y aquellas otras reservadas a la ley ordinaria.

a) Materias reservadas a la ley orgánica.-La ley orgánica -como es bien conocido- se caracteriza en la Constitución por los especiales requisitos de su aprobación, modificación o derogación, que exige,

*mayoría absoluta del Congreso en una votación final sobre el 'conjunto del proyectom (art. 81-2. ${ }^{\circ}$.

Este requisito evidencia que la Constitución pretende conseguir que determinadas materias no puedan ser reguladas sino por ley, en la que necesariamente han de estar de acuerdo la 
mayor parte de los miembros del Congreso. Naturalmente, las materias reservadas a las leyes orgánicas son aquellas que revisten una especial importancia, como son las siguientes:

- Las relativas al desarrollo de los derechos fundamentales y de las libertades públicas (art. 81 de la Constitución);

- las que aprueben los Estatutos de Autonomía (art. 81 de la Constitución);

- las que aprueben el régimen electoral general (art. 81 de la Constitución);

- las demás previstas en la Constitución, como son las relativas a: las bases de la organización militar (art. 8, 2); la institución del Defensor del Pueblo (art. 54); suspensión de ciertos derechos para personas determinadas (art. 55); abdicaciones, renuncias y dudas en el orden de sucesión a la Corona (art. 57, 5); iniciativa popular para la presentación de proposiciones de ley (art. 87, 3); condiciones y procedimento del referéndum (art. 92,3); autorización de celebración de tratados por los que se atribuya a una organización o institución internacional el ejercicio de competencias derivadas de la Constitución (art. 93); funciones, principios básicos de actuación y estatutos de las Fuerzas y Cuerpos de Seguridad (art. 104, 2); Consejo de Estado (artículo 107); regulación de los estados de alarma, de excepción y de sitio (art. 116); Poder Judicial (art. 122); Tribunal de Cuentas (art. 136, 4); alteración de los límites provinciales (art. 141, 1); Comunidades Autónomas en los supuestos del artículo 144; reforma de Estatutos (art. 147, 3); policías locales (art. 148, 1, 22. ${ }^{\circ}$; transferencia o delegación de facultades correspondientes a materias de titularidad estatal (art. 150, 2); iniciativa del proceso autonómico en el supuesto del artículo 151, 1; constitución de la Comunidad Autónoma en el caso del artículo 151, 3; en materia financiera en relación con las Comunidades Autónomas (art. 157, 3); Tribunal Constitucional (art. 165).

b) Materias reservadas a la ley ordinaria.-Junto a las materias reservadas a la ley orgánica, la Constitución reserva otras muchas a la ley ordinaria. Así se comprueba con la simple lectura 
de la misma que remite en múltiples ocasiones a la «ley», palabra que a nuestro juicio utiliza en el sentido de norma con rango de ley, y de «ley ordinaria». Unicamente en los supuestos en que se utiliza la palabra genérica "ley» en relación a materias que - según otros preceptos de la Constitución-están reservadas a una ley orgánica, habrá que entender que no se utiliza en el sentido de ley ordinaria. Así, la sección $1 .^{a}$ del capítulo $2 .^{\circ}$ del título I, «De los derechos fundamentales y de las libertades públicas», regula una materia reservada a la ley orgánica (de acuerdo con el artículo 81 de la Constitución en su interpretación más estricta), por lo que la utilización del término ley, en cuanto afecte al desarrollo de tales derechos y libertades, hay que entenderlo referido a la ley orgánica.

Con esta precisión inicial, entre las materias reservadas a la ley podemos señalar las siguientes:

- Alusión al tratar de los partidos políticos (art. 6), sindicatos de trabajadores y asociaciones empresariales (articu$\operatorname{los} 6$ y 7);

- múltiples referencias en el título I referente a los «Derechos y deberes fundamentales";

- obligación de comparecer a requerimiento de las Cámaras. (art. 76);

- composición, estatuto e incompatibilidades de los miembros del Gobierno (art. 98,4);

- en relación a los órganos de la Administración (art. 103,2); estatuto de los funcionarios públicos, acceso, sindicación, incompatibilidades y garantías de imparcialidad (art. 103,3);

- audiencia de los ciudadanos en el procedimiento de elaboración de las disposiciones administrativas que les afecten; acceso de los ciudadanos a los archivos y registros administrativos; procedimiento de emanación de los actos. administrativos (art. 105); responsabilidad por el funcionamiento de los servicios públicos (art. 106);

- diversas remisiones a la ley en el título VI, relativo al poder judicial;

- posibilidad de reservar al sector público recursos o servicios esenciales, especialmente en caso de monopolio, y asi- 
mismo de acordar la intervención de empresas cuando así lo exigiere el interés general (art. 128,2);

- establecimiento de las formas de participación de los interesesados en la Seguridad Social y en la actividad de los organismos públicos cuya función afecte directamente a la calidad de la vida o al bienestar general (art. 129,1);

- planificación de la actividad económica general para atender a las necesidades colectivas, equilibar y armonizar el desarrollo regional y sectorial y estimular el crecimiento de la renta y de la riqueza y su más justa distribución (artículo 131); composición y funciones del Consejo con funciones en materia de planificación a que se refiere el propio artículo 131;

- regulación del régimen de los bienes de dominio público y de los comunales, el Patrimonio del Estado y el Patrimonio Nacional (art. 132);

- establecimiento de tributos, exigencia de los mismos por las Comunidades Autónomas, beneficios fiscales que afecten a los tributos del Estado, contracción de obligaciones financieras y realización de gastos (art. 133); presupuestos generales del Estado (art. 134); autorización para que el Gobierno pueda emitir Deuda Pública o contraer crédito (art. 135);

- elecciones locales municipales y régimen de concejo abierto (art. 140); funciones de las Corporaciones Locales (artículo 142);

- atribución a todas o algunas de las Comunidades Autónomas de la facultad de dictar normas legislativas para sí mismas en el marco de los principios, bases y directrices fijadas por una ley estatal (art. 150,1); establecimiento de los principios necesarios para armonizar las disposiciones normativas de las Comunidades Autónomas (art. 150,3).

\section{INEXISTENCIA DE UNA RESERVA REGLAMENTARIA}

Las materias reservadas a la ley configuran un ámbito en el que, como es obvio, no existe la posibilidad de dictar reglamentos independientes. La búsqueda de un ámbito de la potestad re- 
glamentaria, independiente de la ley, debe efectuarse, pues, con exclusión de estas materias.

Pues bien, tal búsqueda se dificulta si se tiene en cuenta que la Constitución -acertadamente a nuestro juicio- no reserva materia alguna, de forma expresa, al ámbito de la potestad reglamentaria, sino que parte de la primacía de la Ley como expresión de la voluntad popular (Preámbulo) y, en definitiva, de que la soberanía reside en el pueblo español (art. 1,2). De aquí que corresponde a las Cortes Generales, que representan al pueblo español, el ejercicio de la potestad legislativa del Estado (artículo 66 de la Constitución).

En consecuencia, y al no existir una reserva reglamentaria, la Ley puede regular todas las materias, con lo que en las no reservadas a la misma (reserva material) se producirá una autorreserva, una congelación de rango (reserva formall, ya que las leyes sólo pueden ser modificadas por normas del mismo rango, dado además el principio de jerarquía normativa (art. 9,3).

3. El carácter residual de la potestad REglamentatia del Gobierno

Las consideraciones anteriores permiten afirmar que no existe un ámbito propio y especifico de la potestad reglamentaria del Gobierno, al margen de ley e incardinada a la Constitución. Tal ámbito puede existir eventualmente en las materias no reservadas a la ley y que no sean reguladas por la misma (creando así la reserva formal, en los términos vistos) y también como consecuencia de la deslegalización a que nos referimos más adelante.

Esta solución es lógica, si se tiene en cuenta que la Constitución española viene a configurar un sistema de gobierno que puede definirse como parlamentario. Si la soberania reside en el pueblo español y se manifiesta por medio de la actividad de sus representantes en las Cortes, es lógico que la ley, como forma de expresión de la voluntad soberana, se sitúe por la Constitución en una posición de supremacia y no se limite su posible contenido por razón de la materia. Pero junto a esta razón polí- 
tica (la reserva reglamentaria se ajusta más a un régimen presidencialista como el francés, en que la expresión de la voluntad general y de la soberanía se refleja de forma paralela en la elección del Parlamento y del Presidente que ejerce el liderazgo del Ejecutivo) existen además en el caso español razones de orden técnico, como es la configuración del Estado y de su organización territorial, con reconocimiento del derecho a la autonomía de las nacionalidades y regiones que integran la nación española. La complejidad de las fuentes sería extraordinaria si se sumara a un sistema complejo estatal el resultado de la aplicación de la autonomía y de su proyección en esta materia.

Se llega así, en definitiva, a justificar, desde una perspectiva política y técnica, la afirmación del carácter residual del ámbito propio y específico de la potestad reglamentaria de la Administración.

Pero tal afirmación, con ser exacta a nuestro juicio, remite a la necesidad de efectuar un intento para precisar en qué materias es previsible que se concrete este ámbito residual.

\section{La determinación del POSIBLe Ámbito Residual}

Las consideraciones anteriores nos han llevado a configurar el ámbito de la potestad reglamentaria independiente como una potestad de contenido residual, en la medida en que no podía comprender las materias reservadas a la ley -orgánica u ordinaria- ni aquellas que fueran objeto de reserva formal al ser reguladas por la misma.

En el presente epígrafe se trata de hacer una labor de prospectiva, determinando en qué medida es posible -y previsible- que el mencionado ámbito residual comprenda aquellas materias que la doctrina viene admitiendo, según hemos señalado, como propias de la potestad reglamentaria independiente de la ley: la potestad organizatoria, las relaciones de supremacía especial y las prestaciones positivas a los administrados que inciden de forma favorable sobre los mismos.

Pues bien, como vamos a justificar inmediatamente, ni tan siquiera en estos tres campos es previsible $-\mathrm{y}$ en algún caso 
tampoco legalmente posible- que exista una potestad reglamentaria del Gobierno que se ejerza directamente a partir de la Constitución y sin intermediación alguna de una Ley que regule la materia de que se trate.

a) Potestad organizatoria.-En orden a la potestad organizatoria, el artículo 103,2 de la Constitución establece que,

"Los órganos de la Administración del Estado son creados, regidos y coordinados de acuerdo con la Ley.»

La mera lectura del precepto transcrito evidencia que la Constitución no atribuye directamente ninguna potestad organizatoria al Gobierno (como en la redacción inicial del artículo, que era el 101,2: "La Administración del Estado y sus órganos periféricos son creados, establecidos y coordinados por el Gobierno de acuerdo con la Leym). Por el contrario, la Constitución remite a la Ley, que podrá efectuar una autorreserva si lo estima oportuno.

Pues bien, a nuestro juicio, lo previsible es que se produzca en esta materia un reflejo del escalonamiento jerárquico de las normas. $\mathrm{Y}$ así como algunas instituciones son objeto de regulación por la propia Constitución -como el Gobierno- y otras han de serlo por ley orgánica, según hemos visto - como el Consejo de Estado, por ejemplo-, hay aspectos menos relevantes que la propia Constitución confía a la ley (por ejemplo, composición del Gobierno, art. 98,1), y otros, como el ámbito de la potestad organizatoria del Gobierno y de la Administración, que la Constitución no concreta, y que deberá determinar la ley a la que remite el artículo 103,2 antes transcrito.

En definitiva, lo previsible en esta materia (como antes indicábamos con base en la Constitución italiana y su desarrollo posterior, cuya solución parece inspirar nuestra Constitución) es que la ley establezca las grandes líneas del esquema organizativo estatal, dejando a la potestad reglamentaria su desarrollo concreto y específico.

b) Relaciones de supremacía especial.-En materia de relaciones de supremacia especial, la Constitución tampoco reconoce un ámbito expreso a la potestad reglamentaria del Gobierno, 
sino que, por el contrario, en muchas de estas relaciones reserva expresamente su regulación a la ley. Así sucede, entre los supuestos que antes quedaron señalados al tratar de la reserva de ley, en los casos siguientes:

- Estatuto e incompatibilidades de los miembros del Gobierno (art. 98,4);

- estatuto de los funcionarios públicos, acceso a la función pública de acuerdo con los principios de mérito y capacidad, las peculiaridades del ejercicio de su derecho a sindicación, el sistema de incompatibilidades y las garantias para la imparcialidad en el ejercicio de sus funciones (artículo 103,3);

- estatuto de las Fuerzas y Cuerpos y Seguridad (art. 104,2).

Pero es que además de estos supuestos típicos de supremacía especial nos encontramos, en relación al dominio público, que su régimen juridico ha de regularse por Ley (art. 132,1), que en consecuencia habrá de incluir las situaciones de supremacia especial que puedan producirse (p. ej., los supuestos de uso privativo o anormal, mediante utilización de la técnica concesional).

Debe añadirse todavía que, si bien a los efectos de delimitar las competencias exclusivas del Estado en relación a las Comunidades Autónomas, el artículo 149,1, 18. ${ }^{\circ}$, de la Constitución establece que,

«El Estado tiene competencia exclusiva sobre las siguientee materias: $18 .^{\circ}$... legislación básica sobre contratos y concesiones administrativas.w

La Constitución no establece de forma expresa que esta legislación básica deba tener en todo o en parte rango de ley, pero el propio encuadramiento de la competencia da a entender que deberá tener tal rango, por ser el apropiado y el que mejor corresponde a su función de sentar unos principios básicos que eventualmente puedan ser desarrollados por cada Comunidad Autónoma que asuma tal competencia en su Estatuto.

Por otra parte, como es sabido, las materias de contratos administrativos y de concesiones están reguladas en este momento 
por normas con rango de ley. Y no parece previsible -aunque fuera posible desde una perspectiva constitucional- que esta situación (que por de pronto supone una congelación de rango, una reserva formal) vaya a ser modificada a través de la técnica de deslegalizar tales materias.

En definitiva, como antes indicábamos con carácter general, gran parte del ámbito tradicional de las llamadas relaciones de supremacía especial se encuentra hoy en día sometido al imperio de la ley, con diverso alcance según el tipo de relación de que se trate.

c) Las prestaciones positivas a los administrados que inciden sobre los mismos favorablemente.-Como ha puesto de manifiesto Ruggiero, la Declaración de Derechos de 1789 contenía en potencia tres revoluciones: la liberal, la democrática y la social, que se reflejaron en la propia Revolución francesa, como un resumen y anticipación de todas las luchas políticas y sociales del siglo xix: Esta idea se comprueba fácilmente si se observa cómo se han ido produciendo sucesivamente cada una de estas revoluciones con sus correlativos derechos: los de cuño liberal, los de carácter democrático y los denominados derechos económicos y sociales, que a partir de la Constitución mejicana de 1917 se reflejan normalmente en las posteriores.

De esta forma, a través de un largo proceso de cambio, se ha generalizado la conciencia de que existen unos estándares o niveles mínimos que los poderes públicos deberian garantizar a todo ciudadano, al menos en la medida en que no los disfrute como consecuencia del libre juego social. En este sentido, el reconocimiento de los denominados derechos de carácter económico y social en las Constituciones supone al menos una línea directiva que impone, cuando sea necesaria a tal efecto, la intervención del Estado tendente a garantizar su efectividad práctica. $Y$, dando un paso más en esta línea de tendencia, la doctrina ha hecho notar como la «procura existencial» —dada la situación de menesterosidad social en que la sociedad industrial coloca al ciudadano- se configura como uno de los fines del Estado Social de Derecho (Fonsthoff, L. Martín-Retortillo, Garcia-Pelayo).

Pues bien, dado que nuestra Constitución reconoce todos estos derechos y configura el Estado con un carácter social, podemos 
preguntarnos si en el ámbito de la actividad de prestación de los poderes públicos no podría encontrarse un campo propio de la actividad reglamentaria independiente.

Planteada así la cuestión, debe hacerse notar que aunque en teoría, como ya hemos señalado, la respuesta pudiera ser afirmativa, no podemos ignorar que en la práctica existen razones para sostener que será normalmente negativa. Tales razones son, sustancialmente, las siguientes:

- La efectividad de los denominados derechos económicos y sociales, y, en términos más amplios, de la "procura existencial", supone una parte sustancial de la inversión pública y - dada su importancia- de la acción política. Por ello, es lógico que el legislativo intervenga en esta acción política por medio de las leyes sectoriales correspondientes. y que no se limite a fiscalizar la inversión a través de la Ley de Presupuestos;

- la consecución de la efectividad mencionada exige, en ocasiones, incidir en el régimen jurídico de otros derechos, especialmente los de carácter liberal, cuyo ámbito debe ser delimitado con criterios sociales. Así, por ejemplo, la efectividad del denominado «derecho a disfrutar de un medio ambiente adecuado para el desarrollo de la persona" (artículo 45,1), que no se configura realmente como un derecho, sino como un principio rector de la política social y económica, conduce lógicamente a la necesidad de que se. fijen límites al derecho de propiedad (por ejemplo, en materia urbanística) y al ejercicio de la libertad de empresa (actividades molestas, insalubres, nocivas y peligrosas, por ejemplo).

Estas razones, en parte metajuridicas, se reflejan de forma expresa en nuestra Constitución. En este sentido debe ponerse de relieve que si se examina la Constitución se termina llegando a la conclusión de que también estas materias se encuentran sometidas a 1 principio de reserva de ley, incluso en losı supuestos, que inicialmente parece no ser así. Si tomamos, por ejemplo, el capítulo III del título I, que se refiere a los "principios rectores. de la política social y económica", existen supuestos en que la: 
propia Constitución no remite a la ley de forma expresa, como sucede en el denominado derecho a disfrutar una vivienda digna y adecuada, que regula en su artículo 47,1 , el cual dice así:

«Todos los españoles tienen derecho a disfrutar de una vivienda digna y adecuada. Los poderes públicos promoverán las condiciones necesarias y establecerán las normas pertinentes para hacer efectivo este derecho, regulando la utilización del suelo de acuerdo con el interés general para impedir la especulación.»

Pues bien, la referencia a los poderes públicos y a las «normas parece indicar, en principio, la posibilidad de que sean de carácter reglamentario. Pero resulta que para la efectividad del derecho o disfrutar de una vivienda digna y adecuada el precepto transcrito indica que habrá que regular la utilización del suelo de acuerdo con el interés general, lo que obviamente no puede hacerse sino por ley, ya que supone fijar un límite al derecho de propiedad por razón de su función social, lo que - se repite- ha de hacerse por ley de acuerdo con el artículo 33,2 de la propia Constitución.

Por otra parte, y en la misma línea de razonamiento, debe añadirse que el hecho de que la efectividad de tales derechos y de la «procura existencial» se configuren como los «principios rectores de la política social y económica", conduce de forma inmediata a la previsión de que lógicamente el Legislativo -las Cortes - intervendrán en la plasmación de tales principios a nivel normativo. Previsión lógica que -además- aparece confirmada por la Constitución, que en el capítulo IV de este titulo I, referido a las garantías de las libertades y derechos fundamentales, establece - artículo 53,3- que los principios a que nos referimos sólo podrán ser alegados ante la jurisdicción ordinaria,

«de acuerdo con lo que dispongan las leyes que los desarrollen".

A nuestro juicio, la regulación transcrita debe interpretarse en el sentido de que el desarrollo de tales principios rectores debe llevarse a cabo en el nivel legislativo por normas con rango de Ley, sin perjuicio - como luego veremos- del posible desarrollo de las mismas por disposiciones reglamentarias. 
d) Conclusiones.-Como consecuencia de las consideraciones anteriores, puede afirmarse que el ámbito de la potestad reglamentaria del Gobierno -independiente de la ley- no está previsto en la Constitución, que, sin embargo, deja abierta la posibilidad de que pueda delimitarse de forma residual, en la medida en que determinadas materias no estén reservadas a la ley, o no lo estén en su totalidad, y siempre que, aun en estos casos, no se haya producido o produzca la reserva formal al estar reguladas por ley (congelación de rango).

\section{La remisión como técnica de habilitar al Gobierno PARA EL EJERCICIO DE LA POTESTAD REgLAMENTARIA}

Hemos llegado a la conclusión de que la Constitución no delimita expresamente un campo propio de la potestad reglamentaria del Gobierno, independiente de la Ley, cuyo carácter residual ha quedado ya justificado.

Es, por tanto, necesario plantearse ahora cuál puede ser el ámbito de la potestad reglamentaria dependiente de la Ley, a través de las técnicas de la remisión y deslegalización.

En el presente epígrafe nos referimos a la remisión, que, a nuestro juicio, exige un examen matizado que permita determinar en qué supuestos es posible y, aún más, si ha de ser expresa en todos los casos o cabe admitirla de forma implícita.

En principio parece que no debería haber obstáculo alguno -desde una perspectiva estrictamente jurídica- para que cada ley pudiera autorizar al Ejecutivo a desarrollar su contenido. Esta afirmación inicial requiere, sin embargo, algunas precisiones que -en aras de la mayor claridad- vamos a efectuar siguiendo el mismo esquema que hemos observado anteriormente: materias reservadas a la ley -orgánica y ordinaria- y materias en que se produce la reserva formal o congelación de rango, al estar reguladas por ley.

a) Materias reservadas a la ley orgánica.-En las materias reservadas a la ley orgánica, antes expuestas, la Constitución refleja de forma expresa la finalidad de que tales materias sean reguladas por una ley dotada de especial solemnidad, como es 
la ley orgánica. Tan clara es esta finalidad que tales materias están excluidas de la delegación recepticia - ley delegante y decretos legislativos-, de acuerdo con el artículo 82,1 en relación con el 81 de la Constitución, lo que evidencia la pretensión de que la regulación completa de fondo de tales materias $-\mathrm{y}$ no simplemente los criterios básicos a través de la delegación por medio de una ley de bases, que excluye - sean objeto de ley orgánica.

En consecuencia, parece que la posibilidad de que la ley orgánica habilite al Gobierno para dictar las normas reglamentarias que la desarrollen debe ser excluida. La afirmación se refiere estrictamente al ámbito material reservado a la ley orgánica, que no siempre comprende la totalidad de la materia (por ejemplo, el artículo 8,2 sólo reserva a la ley orgánica los criterios básicos de la organización militar).

En lo demás -es decir, en la parte de la materia no reservada a la ley orgánica- serán aplicables los criterios antes expuestos. Es decir, en la medida en que tampoco esté reservada a la ley ordinaria ni haya sido objeto de reserva formal (regulación por ley), quedará incluida en el ámbito de la potestad reglamentaria independiente de la Administración.

b) Materias reservadas a la ley ordinaria.-En cuanto a las materias reservadas a la ley ordinaria, es clara la finalidad de la Constitución, al efectuar la reserva, de que la ley efectúe una regulación de fondo de tales materias. Sin embargo, puede afirmarse, a nuestro juicio, con carácter general y sin perjuicio de las precisiones que luego se efectúan, que aquí la reserva se refiere a la necesidad de que el Legislativo establezca al menos una regulación básica, bien a través de una ley de bases, bien a través de una ley ordinaria que remita su desarrollo a una norma reglamentaria.

Para justificar nuestra afirmación debe abservarse que en esta materia sí cabe la delegación recepticia (art. 82 de la Constitución), con lo cual, en caso de utilizarla, el Gobierno será el encargado de desarrollar la ley de bases de acuerdo con los principios y criterios establecidos en la misma. El hecho de que el decreto legislativo tenga valor de ley y de que el decreto dictado por remisión tenga valor reglamentario es una diferencia 
que tiene trascendencia en orden a su rango y régimen jurídico. Pero desde la perspectiva que ahora nos interesa, evidencia que la Constitución admite la posibilidad de que el Gobierno complete la regulación básica, que es la que realmente queda reservada al Legislativo, y este dato - que es el capital a nuestro juicio-. sirve para poner de manifiesto el alcance de la reserva de ley en este punto.

c) Posibilidad de admitir la remisión implicita en las materias reservadas a la ley ordinaria.-Partiendo de la afirmación anterior, cabe ahora plantearse si la remisión ha de ser explícita o puede entenderse efectuada de forma implícita.

Para contestar a la cuestión suscitada partimos de lo que consideramos como supuesto normal, que concretamos en la posibilidad de remisión -ya expuesta-y en su carácter expreso. Sin embargo, es necesario determinar si en algún supuesto la posibilidad de remisión -aún expresa- ha de calificarse de excepcional, y también, desde otra perspectiva, si en algún caso puede admitirse -ante el silencio del legislador- la remisión implicita. A continuación nos referimos a cada uno de estos dos supuestos.

En primer lugar, y en relación a la regulación de los derechos y deberes de los ciudadanos reservados a la ley ordinaria (Sección $2 .^{a}$ del capítulo $2 .^{\circ}$ del título I, arts. 30 a 38), es claro que tal remisión habrá de ser objeto de una formulación expresa y detallada, ya que en principio tales derechos sólo pueden ser regulados por ley (art. 53 de la Constitución). Aunque los argumentos antes expuestos nos hacen admitir, en principio, la posibilidad de remisión, es claro, a la vista del artículo 53, que en esta materia tal posibilidad debe interpretarse con criterio restrictivo, y hay que referirla a aquellos supuestos en que sea técnicamente necesaria e inevitable para conseguir la finalidad propuesta por el constituyente (por ejemplo, es técnicamente impensable, en el momento actual, que la función social de la propiedad en relación a cada tipo de bienes sea concretada exclusivamente por la ley; piénsese, por ejemplo, en materia urbanística).

En segundo término, y respecto a las demás materias reservadas a la ley ordinaria, debe sostenerse que en cuanto la ley se 
refiera a materias "administrativas", en las cuales la ejecución de su contenido queda confiado al Gobierno y a la Administración, habrá que admitir la posibilidad de una habilitación implícita para que el Gobierno pueda reglamentar la ley, en cuanto sea técnicamente necesario, pues, en definitiva, el reglamento puede encuadrarse en un sentido amplio entre las medidas necesarias para la ejecución de la ley.

d) Materias objeto de reserva formal.-En las materias administrativas en que se ha producido una incidencia sobre la potestad reglamentaria de la Administración por el hecho de estar reguladas por una ley (reserva formal) estimamos que la potestad reglamentaria sigue subsistiendo en la medida en que no haya sido afectada por tal regulación. En consecuencia, salvo exclusión expresa por parte de la ley, el Gobierno podrá desarrollarla a través del ejercicio de su potestad reglamentaria. La diferencia sustancial -antes y después de la autorreserva- es que el reglamento -en cuanto venga a desarrollar la ley- no será independiente, sino ejecutivo, por cuanto el Gobierno estará vinculado por el principio de jerarquía de las normas no sólo negativa sino positivamente, en el sentido de que la norma reglamentaria deberá partir precisamente de los criterios plasmados por el legislador.

Por otra parte, es claro que en la medida en que la materia no haya sido objeto de reserva formal subsiste la potestad reglamentaria independiente.

\section{REFERENCIA a LA DESLEGALIZACIÓN}

En cuanto a la deslegalización, es decir, la modificación del rango de una ley para rebajarlo, con objeto de que el Gobierno pueda entrar a regular la materia en el ejercicio de su potestad reglamentaria, parece claro que:

- Su aplicación no puede efectuarse en las materias reservadas a la ley -orgánica $u$ ordinaria-, dado que por principio tales materias han de ser reguladas por norma con rango de ley, en los términos ya expuestos; 
- la deslegalización encuentra su campo propio en aquellas materias reservadas formalmente a la ley -reserva formal- en cuanto aquí no existe un fundamento jurídico de fondo que impida la regulación reglamentaria, ya que tales materias si no hubiesen sido reguladas por ley pertenecerian al ámbito propio de la potestad reglamentaria independiente.

Ya hemos indicado antes las razones por las que entendemos que no es previsible que la deslegalización tenga una gran aplicación práctica, a los efectos que ahora interesan, de ampliar el ámbito de la potestad reglamentaria. Y en tal sentido, debe tenerse en cuenta que en ocasiones esta figura se utiliza por la ley a otros efectos, como es el de posibilitar la subsistencia de la anterior, con rango reglamentario, pero sin que ello implique ampliar sustancialmente el ámbito de la potestad reglamentaria, en cuanto la nueva ley viene a contener una regulación de fondo relativa a la misma materia.

\section{LOS DENOMINADOS REGLAMENTOS U ORDENANZAS DE NECESIDAD}

La Constitución prevé también la posibilidad de que el Gobineno pueda dictar reglamentos $u$ ordenanzas de necesidad, si bien las competencias y limitaciones correspondientes quedan remitidas a una ley orgánica (art. 116,1), sin perjuicio de las precisiones que efectúa la propia Constitución en este precepto, y en el 55, a los que luego aludimos.

En todo caso es interesante señalar aquí que la declaración del estado de alarma corresponde al Gobierno - sin previa autorización de las Cortes-, si bien por un plazo máximo de quince días y dando cuenta al Congreso, sin cuya autorización no podrá prorrogarse; mientras que la declaración del estado de excepción sí requiere la previa autorización del Congreso, y el de sitio se declara por el propio Congreso.

Pues bien, como decíamos, la Constitución no regula la incidencia que en orden a la suspensión de derechos puede tener la declaración del estado de alarma (incidencia que sí regula el 
artículo 55 en relación a la declaración de los estados de excepción y de sitio), cuya determinación remite a una ley orgánica.

Esta falta de regulación -que no deja de ser llamativapuede quizá explicarse si se tienen en cuenta las garantias que el constituyente ha previsto para la regulación de los derechos y libertades (principio de reserva de ley en la forma ya vista, prohibición de regularlos por decreto-ley -art. 86-), que contrastan, desde una perspectiva política, con la posibilidad de permitir expresamente que el Ejecutivo pueda suspender alguno de estos derechos. De aqui la remisión a una ley orgánica y la no exclusión de esta posibilidad, aunque no se regula de forma expresa, en relación al estado de alarma.

Es previsible que la ley orgánica sí regule esta suspensión en el caso de la declaración del estado de alarma, aunque lógicamente con un ámbito que en ningún caso podrá ser superior al previsto para el estado de excepción.

\section{Conclusiones}

En virtud de las consideraciones anteriores parece ya posible llegar a las siguientes conclusiones:

a) La Constitución consagra los principios de reserva de ley -orgánica y ordinaria- y de primacia de la ley, que puede regular cualquier materia. En consecuencia, no establece ningún ámbito reservado a la potestad reglamentaria del Gobierno, con independencia de la ley; tal ámbito independiente sólo podrá delimitarse en cada momento con carácter residual, excluyendo las materias reservadas a la ley y las que, al margen de tal reserva, hayan sido objeto de regulación por ley.

b) Este ámbito residual puede completarse a través de las técnicas de remisión y deslegalización, cuya posible utilización por la ley es necesario examinar detenidamente.

c) La remisión no puede utilizarse en las materias reservadas a la ley orgánica, afirmación que se circunscribe estrictamente al ámbito de la reserva en los términos antes expuestos. 
d) La remisión puede utilizarse en las materias reservadas a la ley ordinaria, con carácter general, de forma expresa. Por excepción, no cabe sin embargo admitirla en relación a las leyes que regulen los derechos y deberes de los ciudadanos, sino con carácter excepcional, también de forma expresa, y en la medida en que sea técnicamente necesaria e inevitable para la consecución de los fines establecidos por la Constitución.

Desde otra perspectiva, en relación a las demás materias reservadas a la ley, y como una excepción a la necesidad de que la remisión sea expresa, debe afirmarse que en cuanto la ley se refiera a "materias administrativas", en las cuales la ejecución de su contenido quede confiado al Gobierno y a la Administración, hay que admitir la posibilidad de una habilitación implicita para que el Gobierno pueda reglamentar la ley en cuanto sea técnicamente necesario.

e) En las materias que han sido objeto de reserva formal -o autorreserva- entendemos que, salvo exclusión expresa por parte de la ley, el Gobierno podrá desarrollarla a través del ejercicio de su potestad reglamentaria; la diferencia sustancial -antes y después de la autorreserva- es que el reglamento no será independiente, sino ejecutivo, en la medida en que venga a desarrollar la ley.

f) La Constitución contempla también los reglamentos u ordenanzas de necesidad, siendo de destacar que remite a una ley orgánica la determinación de los efectos que puede producir el relativo a la declaración del estado de alarma, en orden a la. suspensión de los derechos individuales.

\section{Apunte sobre otras cuestiones relacionadas con la potestad reglamentaria}

Creemos haber tratado ya de las cuestiones esenciales que suscita la regulación de la potestad reglamentaria del Gobierno en la Constitución, que es el objeto propio del presente trabajo. No obstante, somos plenamente conscientes de que pueden plantearse muchas otras cuestiones en relación a la potestad regla- 
mentaria, de las que no vamos a ocuparnos en el presente trabajo por exceder de los límites fijados al mismo. Por ello, nos limitamos a apuntar algunas de tales cuestiones con carácter exclusivamente complementario.

\section{La potestad REglamentaRIa DE LOS Ministros}

Una de las cuestiones que podría suscitarse es si al atribuir la Constitución al Gobierno el ejercicio de la potestad reglamentaria (art. 97), ello significa que tal atribución de potestad se realiza de forma exclusiva, de forma tal que implica la desaparición de la potestad reglamentaria atribuida también a otros órganos, singularmente a los Ministros.

Pues bien, basta la mera lectura del mencionado articulo 97 para percibir que tal atribución no se efectúa de forma exclusiva y excluyente. En efecto, tal precepto, por lo que ahora interesa, establece que el Gobierno

aejerce la función ejecutiva y la potestad reglamentaria de acuerdo con la Constitución y las Leyes».

Es decir, que al igual que sería impensable $-\mathrm{y}$ no es previsible que nadie pueda sostenerlo de forma fundada- interpretar el precepto en el sentido de que atribuye al Gobierno la función ejecutiva de forma exclusiva y excluyente, del mismo modo sería incorrecto predicar tal conclusión en cuanto a la potestad reglamentaria.

Por lo demás, en este punto la Constitución no innova respecto a la situación anterior, por lo que entendemos que son perfectamente aplicables por el momento las soluciones previstas por la Ley de Régimen Jurídico de la Administración del Estado y las explicaciones dadas por la doctrina para fundamentar el carácter originario de la potestad reglamentaria del Consejo de Ministros y el derivado - y limitado- de la atribuida a otros órganos. 
2: El PROCEDIMIENTO: EN ESPECIAL, LA POSIBle INTRODUCCIÓN DE NORMAS DE VALOR REGLAMENTARIO A TRAVÉS DE CONVENIOS Y TRATAdOS INTERNACIONALES

El procedimiento de elaboración de las disposiciones administrativas es objeto de otra ponencia, por lo que no vamos a incidir en este punto. Unicamente queremos dejar constancia de que al regular esta materia la Constitución (art. 105) deja claramente establecido que entiende que las disposiciones generales lartículo $105, a)]$ y los actos administrativos [art. 105, $c$ )] son figuras jurídicas distintas, como había puesto ya de relieve la doctrina y la jurisprudencia del Tribunal Supremo.

Por otra parte, tampoco entendemos que esté comprendido en el ámbito de la ponencia un tema tan importante como los tratados o convenios internacionales y la incorporación de sus disposiciones al Derecho interno. Por ello, únicamente debemos senalar que, a nuestro juicio, no se han solucionado los problemas que suscitaba la redacción inicial, que atribuía a los tratados o convenios un valor de superley (art. 6) y que permitia su incorporación en determinados supuestos al ordenamiento interno sin intervención del Legislativo (art. 55, núms. 2, 3, 4), lo que no dejaba de ser llamativo desde la perspectiva del ordenamiento interno $y$, en nuestra opinión, criticable. La Constitución, por el contrario, no hace manifestaciones tajantes acerca del valor de los tratados o converios y regula la intervención del Legislativo con bastante detenimiento, de forma tal que pueda afirmarse -aparte de otros supuestos- que la prestación del consentimiento del Estado para obligarse por medio de tratados o convenios requiere la previa autorización de las Cortes Generales cuando la incorporación de sus disposiciones al Ordenamiento se efectúa con valor interno al nivel de ley, aun cuando este principio no se encuentra establecido con la necesaria claridad.

Ahora bien, esta misma regulación evidencia que el consentimiento de las Cortes no es necesario cuando las disposiciones de los tratados o convenios se incorporan al Ordenamiento interno con el carácter de normas de valor a nivel puramente reglamentario (en este sentido, es también indicativo el contenido del artículo 94,2 de la Constitución, que sólo exige que se informe al 
Senado y al Congreso de la conclusión de los tratados o convenios no relacionados expresamente en los artículos 93 y 94,1 de la propia Constitución). Pues bien, desde la perspectiva del presente trabajo, interesa señalar que por esta vía pueden introducirse en el Ordenamiento normas de valor subordinado a la ley, que, sin embargo, no van a poder ser modificadas por la misma. directamente (como excepción al principio de primacía de la ley y de jerarquía dè las normas), pues, como dice el artículo 96 de la Constitución.

*Los tratados internacionales válidamente celebrados, una vez publicados oficialmente en España, formarán parte del ordenamiento interno. Sus disposiciones sólo podrán ser derogadas, modificadas o suspendidas en la forma prevista en los. propios tratados o de acuerdo con las normas generales del Derecho internacional.»

No se trata ahora de adoptar una posición acerca de esta solución, dada la entidad del tema, que excede además de los límites del presente trabajo. Solamente debemos poner de manifiesto que la solución adoptada supone una distorsión en el sistema de fuentes, aun cuando pueda tener en su àpoyo otras razones juridicas basadas en el Derecho internacional.

3. ALUSIÓN AL RÉGIMEN JURÍdICO Y EL CONTROL DE LA POTESTAD REGLAMENTARIA

En cuanto al régimen jurídico de la potestad reglamentaria; la Constitución se limita a establecer determinados principios, como el de legalidad, jerarquía normativa, publicidad de las normas, irretroactividad de las no favorables (art. 9,3) y el principio de reserva de ley, ya considerado. Asimismo establece el de control por parte de los Tribunales del ejercicio de la potestad reglamentaria (art. 106).

En definitiva, tales principios no suponen ninguna novedad en el Ordenamiento, en cuanto estaban ya incorporados al mismo, por lo que nos limitamos a dejar constancia de su reflejo en la Constitución sin mayor comentario. 


\section{BIBLIOGRAFIA}

Los autores citados en el texto se corresponden con las siguientes obras:

AUBY: "L'obligation gouvernamentale d'assurer l'execution des lois", Juris-Classeur Périodique, 1953, 1080.

ANSchüTz: Theorien über den Begriff der gesetzgebenden Gewalt, $2 .{ }^{2}$ edición, 1901, reedición en Scientia, Aalen, 1971.

Ballbé: Voz «Derecho Administrativo», en la Nueva Enciclopedia Juridica Seix, t. I, Barcelona, 1950, 63.

Betri: «Sulla base giuridica del potere regolamentare», Riv. Dir. Pubbl., 1927.

Cammeo: «Delle manifestazioni della volontá dello Stato nel campo del Diritto amministrativo», en el Tratado dirigido por OrLando, III, 190.

- Corso di Diritto amministrativo (1911-1914), reedición por MIeLe con notas de puesta al dia, en Cedam, Padua, 1960.

Carlassare: Regolamenti dell'esecutivo e principio de legalitá, Cedam, Padua, 1966.

CARHE de Malberg: Contribution á la théorie générale de l'Etat, I, 1920 , reedición por el CNRS, París, 1962.

Colmeiro: Derecho Administrativo Español, I, $1 .^{\text {a }}$ ed., Madrid-SantiagoLima, 1850.

DoUENCE: Recherches sur le pouvoir réglementaire de l'Administration, LGDJ, Paris, 1968.

Duguit: Traité de Droit çonstitutionnel, 5 vol., 3. a ed., París, 1927-30.

Esmein: «De la délégation du pouvoir législatif». Revue Politique et Parlementaire, agosto 1894, 200.

Fernández de Velasco: Resumen de Derecho Administrativo y de Ciencia de la Administración, I, 2. ${ }^{\text {a }}$ ed., Barcelona, 1930.

FleiNen: Institutionen des deutschen Verwaltungstechts, 8. ${ }^{\text {a }}$ ed., 1928, reedición en Scientia, Aalen, 1963.

Fonsthofr: Problemas juridicos de la Administración aportadora de prestaciones, pub. en Sociedad Industrial y Administración Pública, Ed. ENAP, Madrid, 1967.

GaRcía de ENTERRía: Legislación delegada, potestad reglamentaria y control judicial, Tecnos, Madrid, 1970.

- (Tomás Ramón Fennández): Curso de Derecho Administrativo, 2. ${ }^{a}$ ed., Civitas, Madrid, 1975. 
García OvIEdo: Instituciones de Derecho Administrativo, Sevilla, 1927.

Garcia-Pelayo: Las transformaciones del Estado contemporáneo. Ed. Alianza, Madrid, 1977.

García-Thevijano: Tratado de Derecho Administrativo, I, $2 .{ }^{a}$ ed., Ed. Revista de Derecho Privado, Madrid, 1968.

Garnido Falla: Tratado de Derecho Administrativo, I, 5. ${ }^{\text {a }}$ ed. IEP, Madrid, 1970.

Gascón Marín: Tratado de Derecho Administrativo, I, $4 .{ }^{\text {a }}$ ed., Madrid, 1929.

Guarino: «Osservazioni sulla potestá regolamentare». Rass. Dir. Pubbl., 1948, 81.

Hauriov: Précis de Droit constitutionnel, $2 .^{a}$ ed., 1929, reimpresión fotomecánica por el CNRS, Paris, 1965.

- Précis de Droit administratif, 11. a ed., Sirey, París, 1927.

JESCH: Gesetz und Verwaltung, 2. ${ }^{\mathrm{a}}$ ed., Mohr, Tübingen, 1968.

KaUfmann E.: Verwaltung, Verwaltungsrecht (1914), hoy publicado en sus Gesammelte Schriften, I (Autorität und Freiheit), Schwartz, Göttingen, 1960, 75.

LaUbadère: Traité élémentaire de Droit administratif, I, 5. ${ }^{\mathrm{a}}$ ed., LGDJ, Paris, 1970.

Martín Retortillo, L.: aLa configuración juridica de la Administración Pública y el concepto de Daseinvorsorge», en el núm. 38 de la R.A.P., pp. 35 y 53.

MerkL A: Allgemeines Verwaltungsrecht (1927), reedición en Wiss. Buchgesellschaft, Darmstadt, 1969.

MoREAU: Le réglement administratif. Etude théorique et pratique de Droit public français. París, 1902.

NIGRo: Studi sulla funzione organizzaltrice della pubblica Amministrazione, Giuffrè, Milán, 1966.

Posada A.: Tratado de Derecho Administrativo según las teorias filosóficas y la legislación positiva, I, 2.a ed., Madrid, 1923.

Ranelletti: "La potestà legislativa del Governo". Riv. Dir. Pubbl., 1926.

Ragnisco: La legge 31 gennaio 1926 e il Consiglio di Stato, Cedam, Padua, 1931.

Romano Santr: Corso di Diritto amministrativo, Cedam, Padua, 1930.

Royo-Villanova, A. y S,: Elementos de Derecho Administrativo, 24. ${ }^{\text {a }}$ ed., Valladolid, 1965. 
Ruggiero: Historia del liberalismo europeo, Ed. Pegaso, Madrid, 1964. Santamaría de Paredes: Curso de Derecho Administrativo. 3." ed., Madrid, 1891.

ULE: Das besondere Gewaltverhältnis, en «Veröffentlichungen der Vereinigung der Deutschen Staatsrechtslehrer» núm. 15 (1957).

Zanobnn: aL'attività amministrativa e la leggex, Riv. Dir. Pubbl., 1924, 281, hoy también recogido en sus Scritti vari di Diritto pubblico, Milán, 1955, 203.

- «La potestá regolamentare e le norme della Costituzione», Riv. trim. Dir. Pubbl., 1951, 553, y también en Scritti vari, cit., 407. 